\title{
Identifying Emotions and Thoughts Related to Speaking Anxiety: Laying the Groundwork for Designing CBT-based Support Materials for Anxious
}

\section{Learners}

Neil Curry, Kanda University of International Studies, Chiba, Japan

Kate Maher, Kyoto University of Foreign Studies, Kyoto, Japan

Ward Peeters, Kanda University of International Studies, Chiba Japan, and University of Antwerp, Belgium

\begin{abstract}
Students describing feelings of anxiety and a lack of confidence for speaking in a foreign language can be a common phenomenon in the context of Japanese higher education. We believe that cognitive-behavioural therapy (CBT) techniques can be used to help such learners overcome these feelings. A scenario-based questionnaire, adapted from Gkonou and Oxford's MYE (2016), was designed in order to examine a number of speaking situations which were thought to induce anxiety, the emotions students associate with these situations and why they feel them, whether there are any situational factors influencing their perceptions, and what coping strategies they may or may not use. Using data collected from 85 first-year English-language majors, we found that 'You want to say something in English in class, but you don't' was the most negatively rated scenario. This was reported as a frequent occurrence and was also a scenario where they lacked coping strategies to deal with their negative emotions. The data also show that there are notable, significant correlations between how frequently students experience any of the given scenarios and how they rate their emotions, with the more frequently a scenario is experienced, the more negatively it is evaluated. This data will be utilised to design CBT-based activities to reduce anxiety in the foreign language classroom.
\end{abstract}

Keywords: Japanese EFL classroom, cognitive-behavioural theory, Foreign Language Anxiety, language learner emotions, speaking-related anxiety

Foreign Language Anxiety (FLA) has been the subject of much research and discussion since Horwitz, Horwitz and Cope (1986) first developed a means of assessing its prevalence amongst foreign language students. They define FLA as "a distinct complex of self-perceptions, beliefs, feelings, and behaviours related to classroom language learning 
arising from the uniqueness of the language learning process" (Horwitz et al., 1986, p.128). It is probably safe to say that in any language classroom there are students for whom the thought of having to express themselves in another language in front of their peers creates feelings of anxiety, potentially preventing them from speaking and reinforcing a lack of confidence in their abilities. In our context of foreign language learning at Japanese universities, students often report experiencing such situations in which they do not take the opportunity to speak. Silent classrooms are also seen in other institutions in Japan (King \& Smith, 2017), and King $(2013 ; 2014 ; 2016)$ has found evidence for a link between a lack of oral participation in classes and experiences of anxiety.

As educators, we know that FLA is present, and that it can make what should be an enjoyable and meaningful experience stressful and demotivating, limiting students' potential. Therefore, developing means to help learners manage their emotions and increase their confidence should be of importance to any foreign language educator. We have found CBT activities to be successful for individual learners (Curry, 2014; Maher, 2020), and are now developing activities which can be used by groups. The first part of this process is to seek confirmation of what kind of situations and scenarios language students find to be anxiety inducing. This paper aims to inform the field on the thoughts and emotions our students experience in given situations and how they may affect their language learning process. We have adapted Gkonou and Oxford's Managing Your Emotions for language learning (MYE) (2016) to present our students with five scenarios selected by the researchers based on our classroom experiences and reports from students, for which they are asked to state their feelings. Understanding from learners' own words how they perceive and interpret affect in the classroom will result in a more accurate assessment of their situation and inform us on what kind of activities might be suitable to overcome anxiety. It also gives some idea of how widespread such feelings of anxiety are, and how intensely they are held. Additionally, we investigate what, if any, coping strategies students use to deal with anxious situations.

\section{Literature Review}

\section{Negative emotions in foreign language classroom and foreign language anxiety}

Awareness of the dynamic role emotions play in language learning has been increasing in the field of SLA research. This attention has been overdue according to some of the leaders of this area of interest. Boudreau, MacIntyre and Dewaele (2018) state that "prior research in SLA has either ignored emotions, underestimated their relevance, or has studied 
them as a relatively stable individual difference variable" (p. 149). Since Gardner's (1985) work on the influence of motivation to learn, research on emotions has established links with the cognitive elements of language learning (Gkonou, Daubney, \& Dewaele, 2017; MacIntyre, 2007; Sampson, 2018). With these new developments, some have stated that too much attention has been placed on the impact of negative emotions, and more recent work has examined the effects of positive and negative emotions (Boudreau et al., 2018; MacIntyre \& Dewaele, 2014; Piniel \& Albert, 2018; Sampson, 2018). In his study on the diversity of feelings in the foreign language classroom, Sampson (2018) says that a lot of this attention has been on FLA (Horwitz et al., 1986). He describes the extent of this focus as being that "one could be forgiven for believing anxiety to be the default feeling for any L2 learner" (p. 2).

These calls for a more diverse approach to examining emotions in language learning were influential when designing this study. While our motivation for this research is to support students who feel that they want to speak in English but do not due to FLA, we wanted first to see whether our students would report having experienced forms of FLA as a dominant emotion. Furthermore, we wanted to challenge our assumptions from our teaching experience about what emotions students experience in the classroom. However, for a foreign language student, it could be argued that there is a higher likelihood of them experiencing some form of academic anxiety related to foreign language learning than other subjects (Piniel \& Albert, 2018).

When Japanese students speak English in their university classes, it is understandable why they might experience FLA. English is a core subject for high school and university entrance exams which mainly test reading and listening ability. With so much weight resting on these skills, development of speaking and writing skills tends to be sacrificed (Nishino \& Watanabe, 2008; Shachter, 2018). The washback effect often means that students' experience of English from 12 to 18 years old involves little exposure to communicative approaches and few opportunities to speak English aside from pronunciation (Gorsuch, 1998; Hino, 1988; Nishino \& Watanabe, 2008; Osterman, 2014). Toyama and Yamazaki's (2018) findings confirm the influence of this learning experience of Japanese university students. Using a factor analysis for the components of the Foreign Language Classroom Anxiety Scale (FLCAS) (Horwitz et al., 1986) they found that communication apprehension and test anxiety were prevalent. In a high-stakes test-focused environment with a lack of opportunities to try speaking, it is not surprising that some students are affected by a fear of failing and worries about not being able to communicate. 
As well as the washback effect, socio-cultural and socio-psychological elements also play a role in FLA in the Japanese context. King's (2014) investigations into Japanese language learners' silent behaviour and anxiety have found that socio-psychological factors in the classroom inhibits students from speaking as demonstrated in his cognitive-behavioural model of a silent L2 learner's social anxiety (Figure 2) (King \& Smith, 2017). King (2014) defines the foreign language classroom as a social situation that can trigger social anxiety which can lead to silent behaviour due to the social performances that occur in this context. King and Smith (2017) explain that social anxiety is "not an entirely separate phenomenon to foreign language anxiety, rather it represents a deep seam running through the latter construct" (p. 91). Concerning the influence of peers in the Japanese context, peer attitudes towards speaking in class can affect anxiety (Effiong, 2016; Lee-Cunin, 2004). As demonstrated in King's (2014) model, some students worry about being negatively evaluated by their classmates. Not just their speaking ability, but fears of bothering their classmates with their performance - not being understandable, being too loud, or choosing uninteresting topics that would not be enjoyable (Greer, 2000; King, 2013; Nakane, 2007). In relation to teachers, the student-teacher hierarchical relationship has clearly defined roles and behaviours, where the student is the listener and the teacher speaks (Aspinall, 2006). This means that silent participation is expected in-class behaviour, which would not be easy for students to change for just one subject-English, or just because they have entered a university classroom (Nozaki, 1993; Wadden, 1993). So, in addition to triggers of contentspecific anxiety, a foreign language student may also feel anxious about the interpersonal and communicative factors present in a language class (Cassady, 2010; Horwitz, Tallon, \& Luo, 2010). 


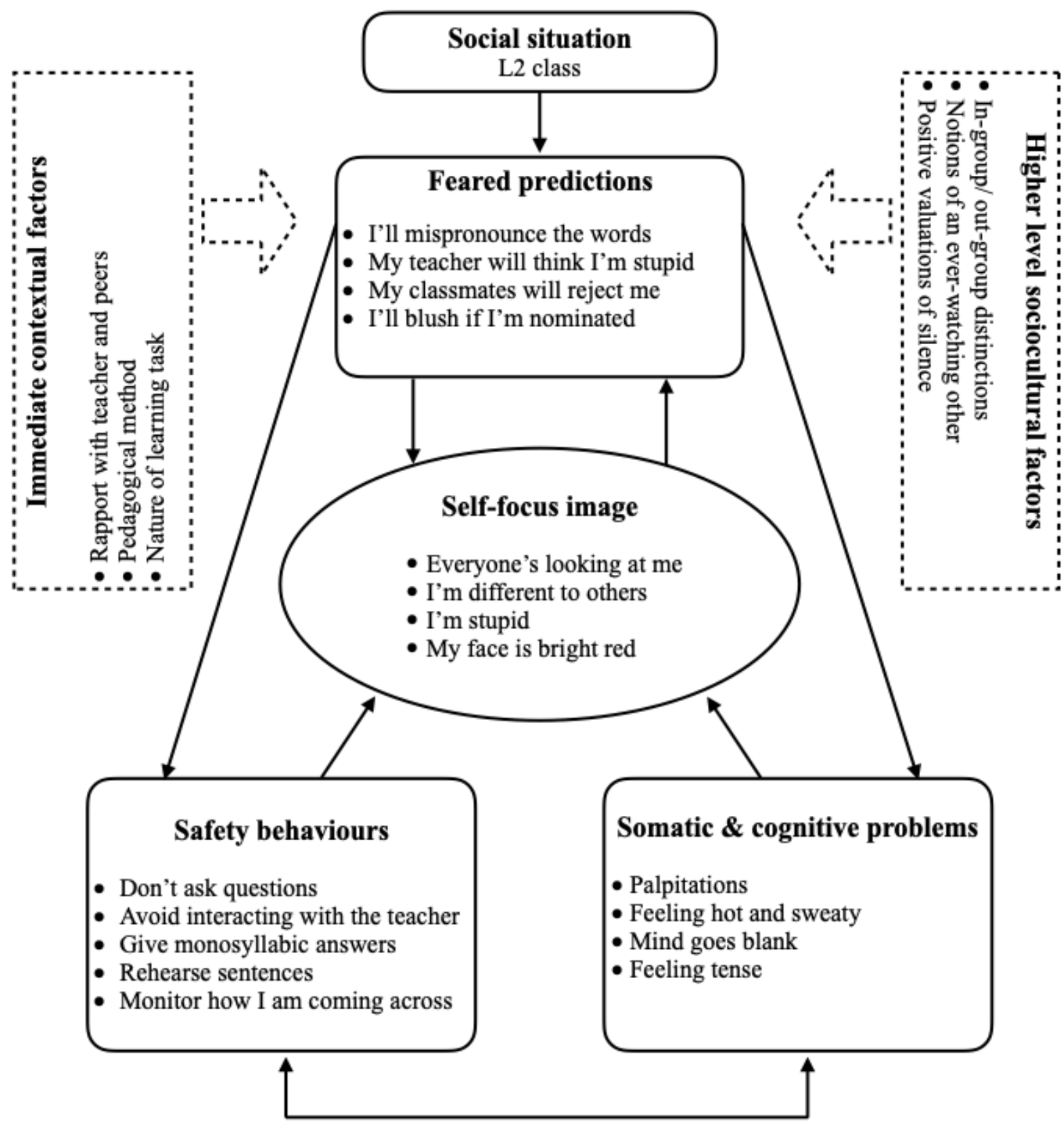

Figure 1. A Cognitive-behavioural Model of a silent L2 Learner's Social Anxiety (King \& Smith, 2017)

Support for anxious Japanese foreign language learners could be argued to be of growing importance as Japan's government is aiming for a more communicative approach to improve speaking skills in foreign language education. These aims have become apparent in curriculum changes which emphasise and promote speaking activities in the classroom, such as evaluated speaking tasks like presentations and speeches (MacWhinnie \& Mitchell, 2017; Teeter, 2017). Nevertheless, despite this top-down emphasis on speaking and moves towards more communicative pedagogy and speaking time in classes, students still appear to miss 
opportunities in the classroom to develop their speaking skills and are hesitant due to negative emotions they experience there (Curry, 2014; Harumi, 2011; King, 2013; 2016; Kurihara, 2006; Shea, 2017). Studies by King $(2013 ; 2016)$ have highlighted the low oral participation in the Japanese university foreign language classroom, finding multiple forms of student silent behaviour and as little as one per cent of initiated talk by students (2013). While not all of this was due to FLA and other negative emotions, it appears that research into students' emotions, thoughts and behaviours related to speaking English could help to find out what support they require to increase their confidence to develop their speaking skills in the classroom.

\section{Developing interventions to help reduce negative emotions related to speaking English in the classroom: $A$ CBT-based approach}

In order to support students to feel more confident about speaking English in the classroom, we intend to develop interventions. The design of these interventions will be based on a cognitive behaviour therapy (CBT) approach and informed by the perspectives of our students. Our ultimate aim is to see how CBT methods can be applied to reduce negative emotions in our classrooms, increase learners' confidence, agency and autonomy, and make the classroom a more comfortable and supportive learning environment for both students and teachers. As CBT methods shaped the structure and purpose of our data collection tool, this section will describe how CBT works and outline how it fits in the context of this project.

CBT can be described as a means of reducing the effects of negative thoughts on behaviour (Stallard, 2019). A premise of CBT is that anxiety results from events being interpreted negatively, which gives rise to negative emotions and sensations. As a result, negative behaviour may ensue. In short, thoughts affect feelings, which in turn create emotions, which then determine behaviour. To give a simple, language learning-related example; a student may

- believe they lack sufficient communicative skills: I don't know enough vocabulary to clearly express what I'm thinking.

- feel ashamed, overly concerned with what others may think: They'll misunderstand me, it will be embarrassing.

- act accordingly with an avoidance strategy: I won't seek out or join a conversation.

This is known as the dysfunctional cognitive cycle (see Figure 2 below). 


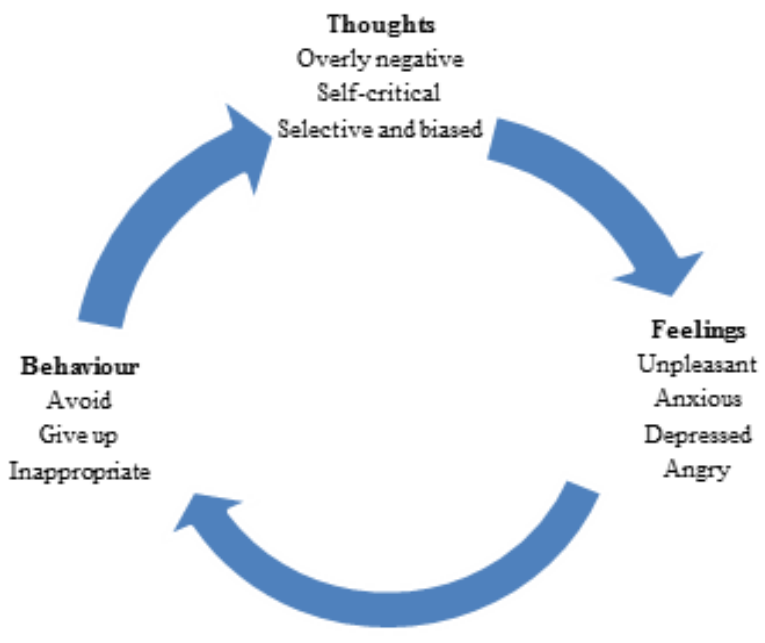

Figure 2. The Cognitive Cycle: A Dysfunctional Cycle (Stallard 2002, p. 7)

CBT identifies three levels of cognition in which thoughts occur, and which the therapy process addresses (Westbrook, Kennerley \& Kirk, 2011). These range from more generalized, deep-rooted beliefs about oneself, to more surface-level automatic thoughts (Stallard, 2009):

1. Negative automatic thoughts (NATs)

Everybody has automatic thoughts, which happen constantly as we interpret the events of our daily lives. Some of these interpretations can be automatically negative if we have an underlying anxiety which stems from certain beliefs, exemplified above as 'I made a mistake, everyone will think badly of me, because mistakes are bad.' If these are not challenged, they may become viewed as truisms. Because NATs influence mood, they are the main focus of CBT therapy, and many activities are designed to aid the anxiety sufferer challenge them in order to renegotiate their beliefs. This process aims to help them come to an alternative, more positive way of thinking about the issue. As these cognitions are the most accessible cognitions, CBT sessions tend to focus on helping the person to recognise them with the aim of changing them into more positive thoughts. Our interventions will also focus on NATs, and we intend to develop activities that help learners to recognize and manage any negative thoughts they have about speaking English in the classroom. These activities will be informed by the data collected in this study, helping us to focus on the negative experiences and perceptions our students have, which we hope will make them more effective for students. 


\section{Core beliefs}

Fundamental ideas or absolute 'truths' about the self and the world, e.g. 'mistakes are a bad thing'. They are not easily accessible and tend to form early through the results of youthful experience. As a result, they generally "are not immediately accessible to consciousness" (Westbrook, Kennerley \& Kirk 2011, p. 10) and cannot be addressed by a short course of interventions; rather, they may change over the long term. It is hoped that the data collected in this study will reveal some students core beliefs to help inform our activity design.

\section{Dysfunctional assumptions}

These often arise from and can be an attempt "to live with negative core beliefs" (Westbrook, Kennerley \& Kirk, 2011, p. 10), shaped as conditional statements, e.g. 'if mistakes are a bad thing, I must not make any!'. Westbrook, Kennerley and Kirk (2011) state that this dysfunctionality stems from a lack of flexibility when people are confronted with real situations. As part of our intervention, we will help students to recognize their negative assumptions and evaluate how they could be affecting their in-class behaviours.

In addition to activities that help students to recognise and manage negative thoughts, another CBT activity we hope to develop for classroom-use is "a hierarchy of feared situations" (Stallard 2009, p. 77). In a CBT session, the person lists situations that range from the least anxiety-inducing, or most relevant of which can be tackled first up to the mostanxiety inducing which they are encouraged to challenge themselves with once they have learnt and practiced how to manage their negative thoughts. To do this as a classroom intervention, we want to firstly confirm what kind of situations students typically experience as anxiety-inducing so that we are able to develop activities for it, as well as using the language that the students use themselves. To do so, we developed the MYE-inspired scenario-based data collection tool used in this study (Appendix A), which focuses on the situations which students often report to us as being anxiety-inducing. Exposure to these situations is a major part of overcoming anxieties, and for our students these situations often involve some aspect of their language class. It is hoped that the completion of the scenario tool can help students to recognize that they are not alone and that others may experience similar problems. This might help them and us in developing skills such as coping strategies 
to manage emotions; and in the language classroom we consider these to be equally important as language skills.

As with learning any skill, students need a period of instruction or 'psychoeducation', by which they will be able to understand the cognitive cycle (Figure 2) and their own thought processes, and understand their own responses to anxiety-inducing situations, strategizing means of challenging "anxiety-increasing self-talk" (Stallard 2009, p. 19). In CBT this is usually done collaboratively with the therapist, but group therapy for social anxiety does exist (Heimberg, 2002), and in our context, if done together as a class, it could allow students to see that often they share the same fears and concerns about their speaking performance. This is a crucial point to consider in the development of anxiety-reduction activities as it is often the opinion and reaction of peers that the anxious student fears the most (King \& Smith, 2017; Yoneyama, 1999). Shared discussion and reflection on shared worries pertaining to the classroom, undertaken in a supportive environment, should allow students to increase the sense of community (Gregersen, MacIntyre, \& Olson, 2017), and recognize that they have a teacher who is aware of potential problems and supportive of them. Horwitz (2017) notes that more teacher support leads to less anxiety, and can, therefore, be seen as a means of actively reducing FLA while creating an enjoyable, stable environment for learning. Lastly, Stallard (2019) remarks that young people often do not ask for help with anxiety issues, so educators may need to take the first step and discover exactly how students might be feeling.

\section{The Study}

\section{Objectives and research questions}

The objective of this study was to investigate the prevalence of speaking-related anxiety and other negative thoughts and emotions of Japanese university language learners. A scenario-based questionnaire was used to gather data to find out what emotions and thoughts students associated with five different scenarios related to speaking English, and what coping strategies students use when experiencing negative emotions. In selecting scenarios, we focused on situations in which students may not speak English due to negative thoughts and emotions. Scenarios included in this study were:

Scenario 1: You have an opportunity to speak English to a non-Japanese person outside of class, but you don't.

Scenario 2: You want to say something in English in class, but you don't. 
Scenario 3: There is another student in your class who you think is a better speaker than you.

You have to do a speaking activity together.

Scenario 4: You make a mistake during a classroom speaking activity, and you receive, or perceive, criticism from another student.

Scenario 5: You make a mistake during a classroom speaking activity, and you receive, or perceive, criticism from the teacher.

To study learners' emotions in given situations, as well as how they cope in these situations, the following research questions were formulated:

RQ1. What emotions do students associate with each scenario?

RQ2. What reasons do students give for assigning these emotions?

RQ3. What situational factors influence students' perceptions in this regard?

RQ4. Do students have coping strategies for situations they perceive as negative?

\section{Context and participants}

The study took place at two medium-sized private universities specialising in foreign languages, located in metropolitan areas in Honshu, the main island of Japan. The questionnaire was given to first-year English-major students whose proficiency levels ranged from lower-intermediate to upper-intermediate based on placement tests by each university. The questionnaire was piloted twice at each site; the first time with 78 students and the second time with 45 students. 85 students completed the final version of the questionnaire. The authors' institutions granted ethical clearance with informed consent in Japanese obtained from all participants before collecting the data.

\section{The questionnaire}

The questionnaire for this study was adapted from Gkonou and Oxford's (2016) Managing Your Emotions for language learning (MYE). This scenario-based questionnaire is designed to find out what emotion-regulation strategies language learners use in 20 hypothetical L2 learning situations. Participants respond to a series of scenarios by writing down their emotions (positive and negative) and emotion-regulation strategies they would or have used in each situation. The MYE was felt to be a good fit for this study. Most importantly, the questionnaire items collect data on language learners' emotions, thoughts and behaviours, which correspond with the CBT elements. Also, the MYE contains several 
open questions to elicit students' perceptions and experiences in their words about speaking English. Piniel and Albert (2018) state that there can be cultural and linguistic differences in how people describe and interpret emotions, as well as individual variation. Therefore, the authors wanted to challenge their assumptions about speaking-related anxiety in the Japanese university context and gain new insights by looking at how the participants themselves described their emotions and thoughts. Finally, the authors felt that the hypothetical style of the scenarios would help to generate responses even from participants who thought they had not experienced those types of situations.

We adapted the MYE to fit our research context by changing some items and reducing the number of scenarios. To link them to CBT elements, we added items to elicit students' thoughts about what causes the emotions they associated with each scenario. Also, we removed items related to teachers helping learners to manage their emotions as we wanted to find out students' independent behaviours and awareness of using coping strategies. We decided to use only five of the MYE's 20 scenarios as we asked participants to complete the questionnaire during class time in case they had any questions. To avoid taking up too much learning time, we aimed for participants to take 20 to 30 minutes to complete the questionnaire. If they did not have enough time, students did not have to complete all the scenarios, or all the questions about the scenarios. They were told that they should start completing the scenario that was most relevant to them first.

For each scenario, participants were asked the same series of questions. The first item asked whether they would feel positive or negative about being in the situation. The MYE has a multiple-choice answer, which we changed to a scale ranging from 0 (positive) to 30 (negative) to find out to what extent they felt it was positive or negative, and giving them the option to put neutral. The second item asks them to write down up to ten emotion words or phrases they associate with the situation. This item helped us to clarify whether participants perceived the situation as positive or negative and gave us new insights through the participants' descriptions. We felt that this was essential given the fact that emotions are personal and culturally dependent (Piniel \& Albert, 2018). In the explanation guide, we included a list of 30 emotion words in Japanese taken from Stallard (2002) with an equal number of positive and negative emotions as a guide for participants, but also to avoid having them think that we were only interested in negative emotions. Thirdly, we asked them to write down why they thought they (would) have these emotions. The next few questions were to find out whether the participant had experienced this situation and the frequency of experiencing it. This item was to help us consider whether these situations could be 'feared 
predictions' or 'direct experiences' (King, 2014). Finally, we asked what coping strategies they had used. This item was to find out how often independent emotion-regulation strategies occurred. In a study by Kondo and Ying-Ling (2004), no significant relationship between language anxiety and frequencies of strategy use were found, suggesting that future research should look at how to increase the effectiveness of such strategies.

After completing the first version of our questionnaire design in English, we translated it into Japanese with a team of four Japanese research assistants -two from each research site- who had high proficiency in English and were familiar with research questionnaire design. For the first round of translation, one research assistant from each site individually translated the questionnaire. The two versions were compared and combined, and then checked by two different research assistants -again, one from each site- and backtranslated into English with the authors to confirm accuracy and nuance. Finally, as a team, we checked the accuracy, nuance and readability for students. We also asked the participants of the two pilot tests to give feedback about the language to make any final changes.

\section{Pilot analysis}

The first and second versions of the questionnaire were piloted with 123 participants, fulfilling Dörnyei and Taguchi's (2009) suggested sample size of 80 to 120 for piloting a questionnaire. The analysis was done using written and verbal feedback received from 23 participants and item analysis. We checked response patterns for missing responses and signs of misunderstanding; for example, some participants responded that they had never experienced the situation but also responded that it happened to them frequently. This led us to add instructions in Japanese next to this item. We also wanted to see to what extent participants responded to each scenario to ascertain whether students were open to answering questions about their emotions, thoughts and behaviours related to language learning. Following this analysis, we made further modifications to the Japanese wording and the order of the scenarios. One translation issue was that in the English version, we intentionally used vague language to prompt various interpretations of the scenario. For example, in Scenario 2 'You want to say something in English in class, but you don't,' was meant to imply that for some reason, they did not speak and missed an opportunity. We avoided using 'you can't' so that students were not guided to reflect on just their ability or proficiency. However, according to participant feedback, this was not a natural translation and may have caused some confusion resulting in fewer responses. After further discussion with the Japanese translators, we decided not to change the wording, but to include more explanation about the 
interpretation of the scenarios at the front of the questionnaire. Finally, we noticed that the scenario with the lowest number of responses was the last one which asked about an outsideof-class speaking situation. Since students were requested to focus on the scenarios which were most applicable to them first, they were free to choose where to start when completing the questionnaire. We decided to reverse the order of the scenarios before the second pilot to see if this affected the response rate. However, reversing the order of the scenarios did not majorly affect response rates for the different scenarios.

In the following section, the emotion words and phrases students associate with the given scenarios are analysed, as well as their interpretation of these emotions and their coping strategies. In order to shed more light on any possible relation between how often students experience a scenario, how they rate it, and whether or not they have any coping strategies for that scenario, correlation and association analyses were conducted. This information allows us to elaborate on the situational factors that come into play, distinguish patterns between factors, and inform future research design.

\section{Results}

In this section, we will first elaborate on participants' emotional rating of the different scenarios, which is represented by a scale equivalent to numbers ranging from 0 (being positive) to 30 (being negative). A summary of these emotions is also provided. Then, we look at the situational factors which might influence participants' ratings, including whether participants have ever experienced the given scenario before, and, if so, how frequently they experience it. Following this, we analyse if participants report on having any coping strategies for a scenario which they rate negatively. Finally, we provide an in-depth analysis of Scenario 2, which was rated the most negatively by the participants.

\section{Positive and negative emotions}

From participants' responses, the mean $(M)$ and standard deviation (sd) scores for all scenarios were calculated. Scenario 5 is rated as the most positive by the participants $(M=$ $8.9, \mathrm{sd}=8.7)$, followed by Scenario $3(M=10.1, \mathrm{sd}=9.6)$ and Scenario $4(M=10.8, \mathrm{sd}=$ 9.7). In general, Scenario 1 is rated more negatively than positively $(M=17.3, \mathrm{sd}=8.8)$ and Scenario 2 is rated as the most negative $(M=18.6 ; \mathrm{sd}=9.4)$. The standard deviation for all scenarios is high, indicating that there does not seem to be a consensus among participants and that there can be a great level of variation between individual respondents when rating their positive and negative emotions. This claim is backed up by the results of a repeated- 
measures ANOVA that was used to analyse if the five means reported on above can be considered equal. The results show, however, that there are significant differences between the situations the students were presented with, based on the ways they rate the scenarios $(\mathrm{F}(4,336)=27.93, \mathrm{p}<.00001)$. To give an idea of what emotions the participants associated with each scenario, Table 1 contains the three most mentioned positive and negative emotions.

Table 1

List of Most Prevalent Emotions for Each Scenario

\begin{tabular}{cll} 
Scenario & Positive emotions & Negative emotions \\
\hline 1 & happy, interested, excited & miserable, insecure, nervous \\
\hline 2 & motivated, excited & miserable, no confidence, insecure \\
\hline 3 & enjoyable, excited, motivated & insecure, nervous, frustrated \\
\hline 4 & happy, motivated, ambitious & ashamed, frustrated, miserable \\
\hline 5 & happy, motivated, ambitious & ashamed, miserable, depressed
\end{tabular}

Because of its negative rating, we would, firstly, like to focus on students' responses to Scenario 2 in our analysis. As already mentioned above, negative emotions are often associated with FLA and, therefore, are of particular interest when studying ways to combat students' feelings of anxiety. Furthermore, because Scenario 2 is classroom-based, this is a good starting point for developing group-focussed activities for FLA reduction.

Participants gave a variety of reasons for their negative feelings in this situation, as shown in Table 2. The 67 responses to Question 10 (Why do you think you would feel this way? Please explain in a few words), were coded by selecting key terms or 'themes' relating to the emotions being expressed and elements from CBT. Of the total, only four responses in the last two categories could be considered positive as they contained no language describing negative feelings or offered some type of solution; all other categories are coded as negative owing to only negative feelings being expressed. 
Table 2

Students' Report on Emotions for Scenario 2

\begin{tabular}{ll}
\multicolumn{1}{c}{ Category } & Total number \\
\hline Unable to talk due to belief they lack linguistic skills & 17 \\
\hline $\begin{array}{l}\text { Negative feelings due to belief in they are unable to speak } \\
\text { (no specific cause given) }\end{array}$ & 12 \\
\hline Lacking confidence / agency & 11 \\
\hline Fear of negative evaluation & 6 \\
\hline Belief in a lack of ability related to studying & 6 \\
\hline Feeling unable to communicate & 4 \\
\hline Negative feelings (no specific cause) & 2 \\
\hline Feeling unable to decide their next step & 2 \\
\hline Positive/ neutral & 2 \\
\hline Ways to improve their situation/ themselves
\end{tabular}

\section{Situational factors: Experience and frequency}

To analyse whether there is any relation between students' report on their emotions for a given scenario, and situational factors such as whether or not they have experienced that scenario before and, if so, how frequently this occurs, levels of correlation and association have been calculated for these variables. Calculating the level of correlation (based on Pearson's r) was possible for data sets with two ordinal variables, such as the rating of emotions (on a scale from 0 (positive) to 30 (negative)) and frequency (on a scale from 0 (never) to 30 (all the time)). In their meta-analysis of effect sizes in L2 research, Plonsky and Oswald (2014) make a strong case for interpreting $r$ that is close to .25 (or a probability of $6 \%$ ) as a small effect size, .40 (or a probability of 16\%) as medium, and .60 (or a probability of $36 \%$ ) as large.

To calculate if there is a relation between students' rating of their emotions and frequency, levels of association were calculated (based on $\eta^{2}$ ) to determine if students' experience with a given scenario (nominal data: 1 (yes) or 2 (no)) relates to how they rate that scenario (Nero et al., 2018). The ETA coefficient $\left(\eta^{2}\right)$ is analogous to Pearson's $r^{2}$ and ranges between 0 and 1 . As a rule of thumb, when $\eta^{2}>0.14$, variables are closely related or, in other words, there is a large effect size. It is not possible to calculate the level of correlation (using $\mathrm{r}^{2}$ ) in this regard since Pearson requires two ordinal variables and no nominal ones. 


\section{Experience}

More than three quarters of the respondents indicate that they have experienced Scenarios 1, 2 and 3 before, while about two thirds have experienced Scenario 5 before and less than half has experienced Scenario 4 before, as indicated in Table 3.

Table 3

Students' Experience with the Given Scenarios

\begin{tabular}{ccc} 
Scenario & Experience & No experience \\
\hline 1 & $80.3 \%$ & $19.7 \%$ \\
\hline 2 & $87.1 \%$ & $12.9 \%$ \\
\hline 3 & $76.6 \%$ & $23.4 \%$ \\
\hline 4 & $41.3 \%$ & $58.7 \%$ \\
\hline 5 & $68.4 \%$ & $31.6 \%$
\end{tabular}

When looking at emotions, for Scenario 1, we see that people who have experienced the scenario rate their emotions more negatively, and that people who have not experienced the scenario before rate their emotions more positively. Statistically, however, with $\eta^{2}=0.0295$, variance in ratings can hardly be associated with whether or not learners have experienced this scenario before, as shown in Figure 3. Across the five scenarios, it has been found that any variation in students' ratings of their emotions can barely be associated with whether or not they had experienced the scenarios before. 
Scenario 1

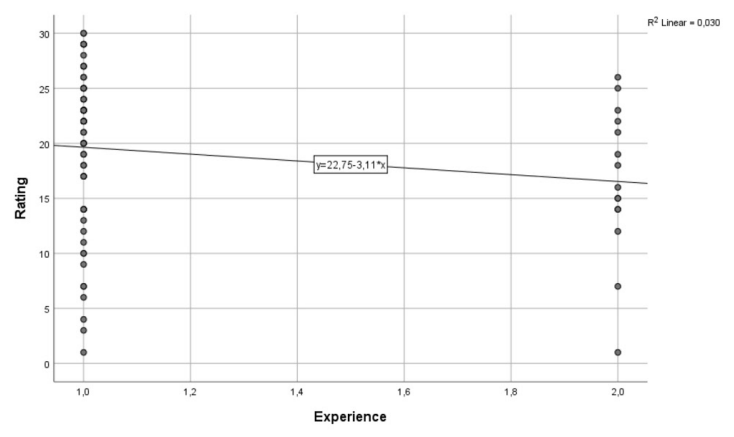

Scenario 3

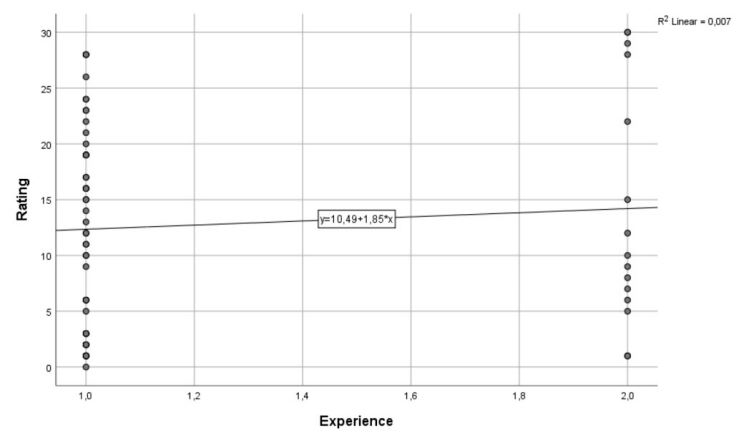

Scenario 5

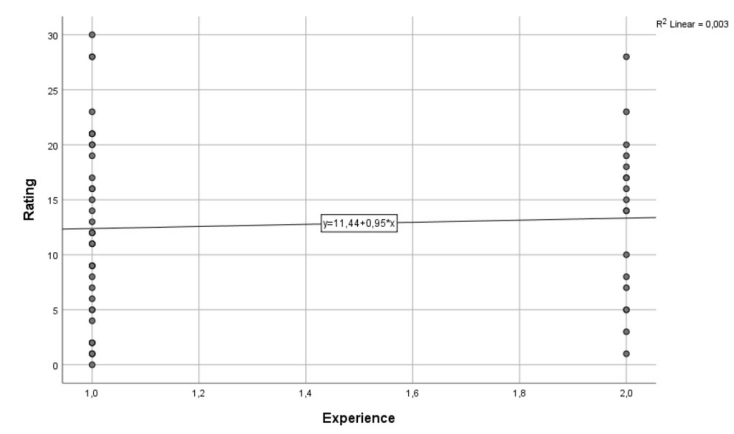

Scenario 2

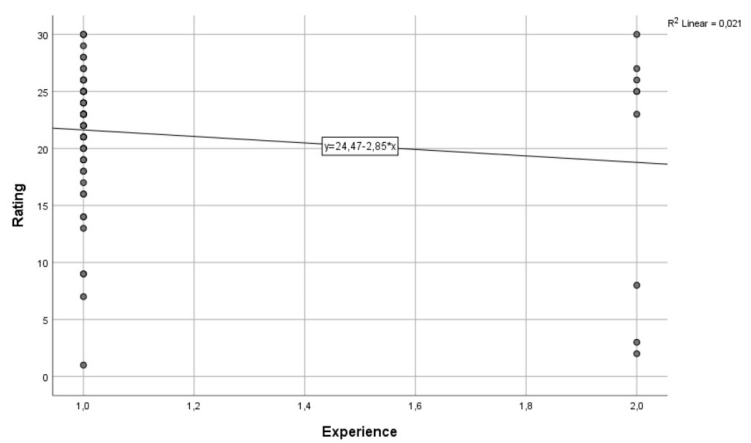

Scenario 4

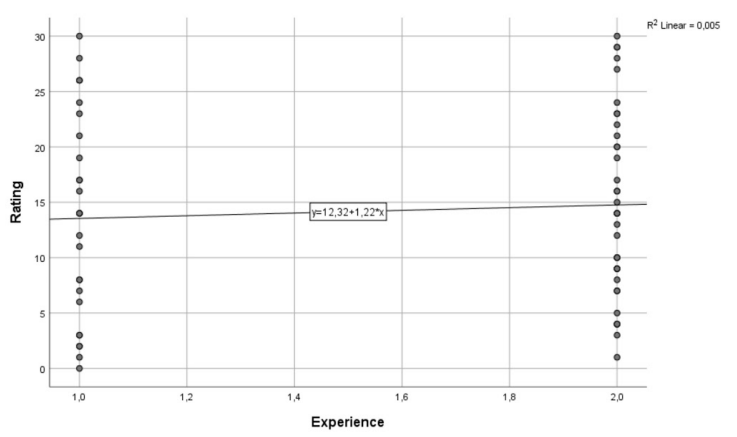

Figure 3: Scatter Plots on Experience and Emotions. The X-axis (Experience) Includes 1 (Yes) and 2 (No). The Y-axis (Rating) Ranges from 0 (Positive) to 30 (Negative).

For Scenario 2, participants who have experienced the scenario also rate their emotions more negatively. With $\eta^{2}=0.0213$, variance in ratings can barely be associated with whether or not learners had experienced this scenario before. For Scenarios 3, 4 and 5, people who have experienced the scenarios rate their emotions more or less the same compared to those who have not experienced these scenarios before. Statistically, with $\eta^{2}=0.0074$ for 
Scenario 3, $\eta^{2}=0.0049$ for Scenario 4 and $\eta^{2}=0.0031$ for Scenario 5, variance in ratings cannot be associated with whether or not learners had experienced these scenarios before.

\section{Frequency}

Looking at the relationship between how frequently a scenario is experienced and how emotions are rated, there are significant correlations to be observed. For Scenario 1, there is a statistically highly significant correlation $(\mathrm{p}>0.01)$ between how frequently a student experiences a given situation and how they rate their emotions, with the more frequently a scenario is experienced the more negatively it is evaluated. For Scenario 1, there is a moderate correlation between the variables (based on $\mathrm{r} 0.498, r^{2}=0.248$ ), as shown in Table 4, below.

Table 4.

Correlation Between Students' Rating of Emotions and Frequency

\begin{tabular}{|c|c|c|c|c|c|c|c|c|c|c|c|}
\hline \multicolumn{4}{|c|}{ Scenario 1} & \multicolumn{4}{|c|}{ Scenario 2} & \multicolumn{4}{|c|}{ Scenario 3} \\
\hline & & Rating & Frequency & & & Rating & Frequency & & & Rating & Frequency \\
\hline \multirow[t]{3}{*}{ Rating } & $\begin{array}{l}\text { Pearson } \\
\text { Correlation }\end{array}$ & 1 &, $498^{* *}$ & Rating & $\begin{array}{l}\text { Pearson } \\
\text { Correlation }\end{array}$ & 1 & , $543^{* *+4}$ & Rating & $\begin{array}{l}\text { Pearson } \\
\text { Correlation }\end{array}$ & 1 &, $256^{*}$ \\
\hline & Sig. (2-tailed) & & ,000 & & Sig. (2-tailed) & & ,000 & & Sig. (2-tailed) & & ,018 \\
\hline & $\mathrm{N}$ & 85 & 85 & & $\mathrm{~N}$ & 85 & 85 & & $\mathrm{~N}$ & 85 & 85 \\
\hline \multirow[t]{3}{*}{ Frequency } & $\begin{array}{l}\text { Pearson } \\
\text { Correlation }\end{array}$ &, $498^{* *}$ & 1 & Frequency & $\begin{array}{l}\text { Pearson } \\
\text { Correlation }\end{array}$ &, $543^{* * *}$ & 1 & Frequency & $\begin{array}{l}\text { Pearson } \\
\text { Correlation }\end{array}$ &, $256^{*}$ & 1 \\
\hline & Sig. (2-tailed) & , 000 & & & Sig. (2-tailed) & ,000 & & & Sig. (2-tailed) & ,018 & \\
\hline & $\mathrm{N}$ & 85 & 85 & & $\mathrm{~N}$ & 85 & 85 & & $\mathrm{~N}$ & 85 & 85 \\
\hline
\end{tabular}

\begin{tabular}{|c|c|c|c|c|c|c|c|}
\hline \multicolumn{4}{|c|}{ Scenario 4} & \multicolumn{4}{|c|}{ Scenario 5} \\
\hline & & Rating & Frequency & & & Rating & Frequency \\
\hline \multirow[t]{3}{*}{ Rating } & $\begin{array}{l}\text { Pearson } \\
\text { Correlation }\end{array}$ & 1 &, $244^{*}$ & Rating & $\begin{array}{l}\text { Pearson } \\
\text { Correlation }\end{array}$ & 1 &, $319^{* *}$ \\
\hline & Sig. (2-tailed) & & ,024 & & Sig. (2-tailed) & & ,003 \\
\hline & $\mathrm{N}$ & 85 & 85 & & $\mathrm{~N}$ & 85 & 85 \\
\hline \multirow[t]{3}{*}{ Frequency } & $\begin{array}{l}\text { Pearson } \\
\text { Correlation }\end{array}$ & ,244* & 1 & Frequency & $\begin{array}{l}\text { Pearson } \\
\text { Correlation }\end{array}$ &, $319^{* *}$ & 1 \\
\hline & Sig. (2-tailed) & ,024 & & & Sig. (2-tailed) & ,003 & \\
\hline & $\mathrm{N}$ & 85 & 85 & & $\mathrm{~N}$ & 85 & 85 \\
\hline
\end{tabular}

For the other scenarios, there is also a statistically highly significant correlation $(\mathrm{p}>$ 0.01 or $\mathrm{p}>0.05$ ) between how frequently a student experiences a specific situation and how they rate their emotions, with the more frequently a scenario is experienced the more negatively it is evaluated. For Scenario 2, there is a medium to strong correlation between the two variables, i.e. the report on emotion is likely to depend on how many times a student has been in that specific situation. We can also observe medium correlations for Scenario 3 and for Scenario 5, and a weak to medium correlation between these variables in Scenario 4. 


\section{Coping strategies}

We also analysed whether students reported on having coping strategies when experiencing these scenarios using the following question; If you tried to manage your emotions in this situation, how did you do so? Examples for Scenario 2 included taking action to improve the situation ("yes, I made sentences in my head then uttered them") or awareness and acceptance of the situation ("hold back my feeling. Suppress it"). For Scenarios 1 and 2, about a third (31.8\% for Scenario 1 and 34.1\% for Scenario 2) reported on having coping strategies while about a tenth (9.4\% for Scenario 1 and $10.6 \%$ for Scenario 2$)$ reported on having no coping strategies at all. A number of students skipped this question (58.8\% for Scenario 1 and 55.3\% for Scenario 2). For Scenario 3, about a quarter (27.1\%) reported on having coping strategies while about a tenth (10.6\%) reported on having no coping strategies. $62.3 \%$ did not answer this question. For Scenario 4 and 5, more than three quarters of the students did not reply to this question. Because of these low response rates across all five scenarios, it is safe to infer that students regarded this question to be challenging. Enough data was collected, however, to make inferences for the first three scenarios. For scenarios 4 and 5, too few students replied, which makes it impossible to make any valid inferences about coping strategies for these scenarios.

We looked at the relation between having coping strategies and emotional rating for the three scenarios. For Scenario 1, we can see equal ratings for people who do and for people who do not have coping strategies. Statistically, with $\eta^{2}=0.0005$, variance in emotional ratings cannot be associated with having coping strategies or not, as shown in Figure 4. 

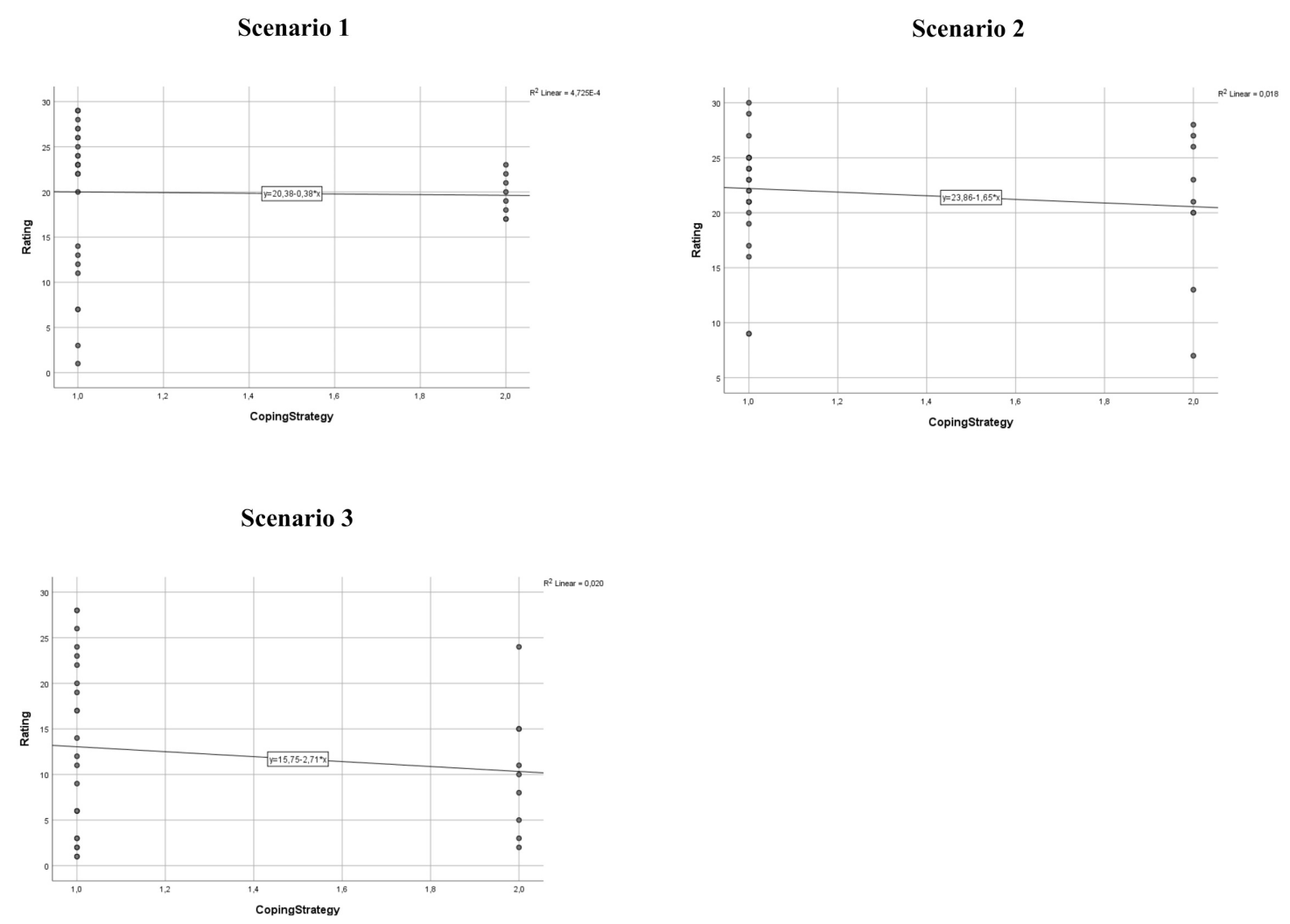

Figure 4: Scatter Plots on Experience and Emotions. The X-axis (Coping Strategies) Includes 1 (Yes) to 2 (No). The Y-axis (Emotional Rating) Ranges from 0 (Positive) to 30 (Negative).

For Scenarios 2 and 3, we can observe fairly equal ratings for people who do have and for people who do not have coping strategies as well. With $\eta^{2}=0.0182$ for Scenario 2 and $\eta^{2}$ $=0.0201$ for Scenario 3, there are very weak levels of association to be observed. In other words, variance in ratings can barely be associated with people reporting on having coping strategies or not. For Scenarios 4 and 5, not enough students reported on whether or not they had coping strategies. Due to the small sample size, no statistical analyses could be conducted.

\section{Discussion}

From the results, we can conclude that students associate Scenario 2 ('You want to say something in English in class, but you don't') with negative emotions the most. We also know from their responses that they experience this scenario most often. Looking at correlation coefficients between the variables 'frequency' and 'emotion', we can infer that the more a student has experienced this scenario, the worse they feel about it. On the other hand, a third of the students report on having coping strategies to deal with this situation, which is the highest number observed. A second situation that was rated more negatively than 
positively was Scenario 1 ('You have an opportunity to speak English to a non-Japanese person outside of class, but you don't'). Students experience this situation often too. Similar to Scenario 2, we can infer that students who have experienced this scenario more often have more negative emotions associated with it. A third of the students report on having coping strategies to deal with this situation, the second highest number observed. Scenario 3 ('There is another student in your class who you think is a better speaker than you. You have to do a speaking activity together') is also experienced quite often by the students but is rated more positively than negatively. A quarter of the students report on having coping strategies to deal with this situation. Scenario 5 ('You make a mistake during a classroom speaking activity, and you receive, or perceive, criticism from the teacher') was experienced less often and is rated more positively than negatively as well. The same goes for Scenario 4 ('You make a mistake during a classroom speaking activity, and you receive, or perceive, criticism from another student'), which is rated as most positive.

Based on the levels of association between the different variables, variation in students' ratings of their emotions can barely be associated with whether or not they have experienced the scenarios before. When students have experienced a given situation, however, there is a (highly) significant correlation between how frequently they have experienced it and how they rate their emotions; the more often a situation is experienced, the more respondents associate negative emotions with it. Finally, whether or not students report on having coping strategies can only slightly (or not) be associated with how positively or negatively they feel about the situation.

These results might indicate that those who have experienced these scenarios have had bad experiences with them and, thus, now associate them with negative emotions, feeding and sustaining the dysfunctional cycle described above. It suggests that a psychoeducational approach which shows students how their cognitions might be affecting their behaviour, and which can empower them to make changes could lead to more positive perceptions. At the same time, those who have not experienced these scenarios might find it difficult to associate any emotions with a situation they have not yet encountered. Still, it is useful to find out how they might feel or react in this situation. We can argue that a student who has knowledge of coping strategies can use these for any stressful situation which might arise in the future, or they might possess good advice or ideas which they can share with their peers.

Additionally, from the analysis of Scenario 2, what is most apparent from the responses is students' beliefs that they lack an essential skill or the quality of being able to do something (refer to Appendix B for list of responses). This suggests that students do not 
speak because they feel that they cannot express what they want to say, or lack confidence, so they keep quiet. The most important point here is that according to the participants' responses, these negative thoughts affect their in-class behaviours as they do not try to speak. If they did, they might build up positive speaking experiences, but their lack of verbal participation means that they are unable to produce the evidence to disprove their negative thoughts. CBT-based activities to help them challenge their thinking and encourage what might be a more positive self-appraisal of their abilities could be valuable here.

In terms of the limitations of this study, we found that the questionnaire did not provide the detail hoped for regarding use of coping strategies. In accordance with the fourth research question, we found that many students who responded to this question do have coping strategies, especially for the most negatively-rated Scenario 2. However, more information is needed to know how well these strategies work, and whether they were developed as a direct response to the scenario being experienced. This may be due to the wording of the question which asked participants to write down how they control their emotions in each scenario. Also, a large number of participants left these items blank, which may suggest that they did not understand the question, or that if they do not control their emotions, they should leave it blank. This item needs to be reworded to get a higher response rate to generate more data, including an option for students to report that they do not try to control their emotions. For our own study, we have already adjusted the question into two parts, adding a fixed yes/no question to find whether participants actually have a coping strategy, before asking for details about the strategy itself. Another limitation, linked to low response rates for some of the questions, is the time it takes to complete a questionnaire in class. Because of time restraints, students might opt to answer questions they think are simpler first and not spend time thinking about more challenging ones. Future projects should, therefore, consider whether additional time needs to be allocated to ensure proper data collection on all variables in the study. In order to answer the questions of how students develop their own means to cope with negative emotions and raise confidence, and how we might be able to utilise these ideas for the benefit of their peers will be the subject of further investigation, as will the development of activities to help learners cope with situations beyond the classroom.

\section{Conclusion}

In summary, we found that the questionnaire was a useful means for achieving our goals. We found out how students perceive five in-class speaking situations and we chose to 
see if these situations would be worth developing into CBT-based activities aimed at reducing students' anxiety about speaking in class. Also, we gathered data on what negative thoughts and emotions students report that they experience, or might experience, in these situations to help inform the activities. To answer the first research question, we found that students attribute more negative feelings to situations when they want to say something but are unable to; inside and outside of the classroom. In accordance with the second research question, students report on feeling predominantly insecure, ashamed or frustrated when being in such a situation. An important situational factor was frequency in this regard. Answering the third research question, the more experience students had with a given scenario, the more negatively they rated it. The fourth research question proved to be rather challenging to answer conclusively. For some scenarios, not enough data was collected on students' coping strategies. However, according to the responses we did receive, we found that students do tend to have coping strategies for scenarios they have experienced more often, and which they have rated more negatively. Nevertheless, more research should be conducted to answer this question.

We were able to provide empirical data to support and challenge our assumptions about whether the five situations we selected are perceived as anxiety-inducing by students. We were surprised to find that making mistakes and receiving negative feedback from peers and teachers was not rated as the most negative, and in fact, was viewed as a positive experience by many. This data has helped us to identify and will help us to concentrate our efforts on the situations which generate the most negative feelings.

The MYE is a valuable instrument for teachers and researchers who want to collect detailed information on students' perceptions of scenarios to identify situations that may cause speaking-related anxiety. As the instrument is easily adaptable to suit the purpose of the research context, the data produced can help to not only gain a deeper understanding of how students think and feel but also to inform future interventions such as in-class activities. We hope that by using the thoughts and phrasing used by the students to report their perceptions, the activities can be tailored more specifically for learners, making the activities more effective. A further practical application of this modified version of MYE is as an in-class activity. It could be used to ask students collectively about how they feel about speaking and a way to show them that many of their peers share similar worries. This could then be an ideal starting point from which to introduce other activities where students can share their ideas, challenges and solutions, leading to a more relaxed and productive classroom atmosphere conducive to learning (Peeters, 2018). Doing this activity with a new class will 
allow us to say to the students "this is how you feel now - how do you want to feel? Together let's think how to achieve that." The next steps of this project will focus on developing and evaluating these practical applications. We aim to create informed CBT-based activities from this data that help anxious students to learn how to recognise and balance out their negative thoughts to improve their confidence to use the class as a place to practice speaking.

\section{References}

Aspinall, R. W. (2006). Using the paradigm of 'small cultures' to explain policy failure in the case of foreign language education in Japan. Japan Forum, 18(2), 255-274.

Boudreau, C., MacIntyre, P. D., \& Dewaele, J. M. (2018). Enjoyment and anxiety in second language communication: An idiodynamic approach. Studies in Second Language Learning and Teaching, 8(1), 149-170. doi:10.14746/ssllt.2018.8.1.7

Cassady, J. C. (Ed.) (2010). Anxiety in schools: The causes, consequences, and solutions for academic anxieties (Vol. 2). New York, NY: Peter Lang.

Curry, N. (2014). Using CBT with anxious language learners: The potential role of the learning advisor. Studies in Self-Access Learning Journal, 5(1), 29-41. doi:10.37237/050103

Dörnyei, Z., \& Taguchi, T. (2009). Questionnaires in second language research: Construction, administration, and processing (2nd ed.). New York, NY: Routledge.

Effiong, O. (2016). Getting them speaking: Classroom social factors and foreign language anxiety. TESOL Journal, 7(1), 132-161. doi:10.1002/tesj.194

Gardner, R. C. (1985). Social psychology and second language learning: The role of attitudes and motivation. London, UK: Edward Arnold.

Gkonou, C., \& Oxford, R. L. (2016). Questionnaire: Managing your emotions for language learning. Colchester, UK: University of Essex.

Gkonou, C., Daubney, M., \& Dewaele, J. M. (Eds.). (2017). New insights into language anxiety: Theory, research and educational implications. Bristol, UK: Multilingual Matters.

Gorsuch, G. J. (1998). Yakudoku EFL instruction in two Japanese high school classrooms. JALT Journal, 20(1), 6-32. Retrieved from https://jaltpublications.org/sites/default/files/pdf-article/jj-20.1-art1.pdf

Greer, D. L. (2000). "The Eyes of Hito": A Japanese cultural monitor of behaviour in the communicative language classroom. JALT Journal, 22(1), 183-195. 
Gregersen, T., MacIntyre, P. D., \& Olsen, T. (2017). Do you see what I feel? An idiodynamic assessment of expert and peer's reading of nonverbal language anxiety cues. In C. Gkonou, M. Daubney \& J. M. Dewaele (Eds.), New insights into language anxiety: Theory, research and educational implications. (pp. 110-134). Bristol, UK: Multilingual Matters.

Harumi, S. (2011). Classroom silence: voices from Japanese EFL learners. ELT Journal, 65(3), 260-269. doi:10.1093/elt/ccq046

Heimberg, R. G. (2002). Cognitive-behavioural therapy for social anxiety disorder: Current status and future directions. Biological Psychiatry, 51(1), 101-108. doi:10.1016/s0006-3223(01)01183-0

Hino, N. (1988). Yakudoku: Japan's dominant tradition in foreign language learning. JALT Journal, 10(1), 45-53.

Horwitz, E. K., Horwitz, M. B., \& Cope, J. (1986). Foreign language classroom anxiety. The Modern Language Journal, 70(2), 125-132. doi:10.1111/j.1540-4781.1986.tb05256.x

Horwitz, E. K., Tallon, M., \& Luo, H. (2010). Foreign language anxiety. In J. C. Cassady (Ed.), Anxiety in schools: The causes, consequences, and solutions for academic anxieties (Vol. 2, pp. 96-115). New York, NY: Peter Lang.

Horwitz, E. K. (2017). On the misreading of Horwitz, Horwitz and Cope (1986) and the need to balance anxiety research and the experiences of anxious language learners. In C. Gkonou, M. Daubney \& J. M. Dewaele (Eds.), New insights into language anxiety: Theory, research and educational implications (pp. 31-47). Bristol, UK: Multilingual Matters.

King, J. (2013). Silence in the second language classroom. Basingstoke, UK: Palgrave Macmillan.

King, J. (2014). Fear of the true self: Social anxiety and the silent behaviour of Japanese learners of English. In K. Csizér \& M. Magid (Eds.), The impact of self-concept on language learning (pp. 232-249). Clevedon, UK: Multilingual Matters.

King, J. (2016). Classroom silence and the dynamic interplay between context and the language learner: A stimulated recall study. In J. King (Ed.), The dynamic interplay between context and the language learner (pp. 127-150). Basingstoke, UK: Palgrave Macmillan.

King, J., \& Smith, L. (2017). Social anxiety and silence in Japan's tertiary foreign language classrooms. In C. Gkonou, M. Daubney \& J. M. Dewaele (Eds.), New insights into language anxiety: Theory, research and educational implications (pp. 91-109). Bristol, UK: Multilingual Matters.

Kondo, D. S., \& Ying-Ling, Y. (2004). Strategies for coping with language anxiety: The case of students of English in Japan. ELT Journal, 58(3), 258-265. doi:10.1093/elt/58.3.258 
Kurihara, N. (2006). Classroom anxiety: How does student attitude change in English oral communication class in a Japanese senior high school? Accents Asia, 1(1), 34-68.

Lee-Cunin, M. (2004). Student views in Japan: A study of Japanese students' perceptions of their first years at university. Lancaster, UK: Fieldwork Publications.

MacIntyre, P. D. (2007). Willingness to communicate in the second language: Understanding the decision to speak as a volitional process. The Modern Language Journal, 91(4), 564-576. doi:10.1111/j.1540-4781.2007.00623.x

MacIntyre, P. D., \& Dewaele, J. M. (2014). The two faces of Janus? Anxiety and enjoyment in the foreign language classroom. Studies in Second Language Learning and Teaching, 4(2), 237-274. doi:10.14746/ssllt.2014.4.2.5

MacWhinnie, S. G., \& Mitchell, C. (2017). English classroom reforms in Japan: A study of Japanese university EFL student anxiety and motivation. Asian-Pacific Journal of Second and Foreign Language Education, 2(7), 1-13. doi:10.1186/s40862-017-0030-

Maher, K. (2020). A cognitive-behavioural theory-based approach to examining L2 learners' silent behaviour and anxiety in the classroom. In J. King \& S. Harumi (Eds.), East Asian perspectives on silence in English language education (pp.80-104). Bristol, UK: Multilingual Matters.

Nakane, I. (2007). Silence in intercultural communication: Perceptions and performance. Philadelphia, PA: John Benjamins.

Nero, J. G. A. C., Orbiso, B. J., Mahusay, E. A., Suan, T. P., Cui, A. R., \& Soroño-Gagani, F. (2018). A linear correlation analysis of student engagement and level of understanding among Grade 11 Humanities and Social Sciences Students. American Journal of Humanities and Social Sciences Research, 2(8), 41-47. Retrieved from https://issuu.com/ajhssr.editor/docs/f18284147

Nishino, T., \& Watanabe, M. (2008). Communication-oriented policies versus classroom realities in Japan. TESOL Quarterly, 42(1), 133-138. doi:10.1002/j.15457249.2008.tb00214.x

Nozaki, K. N. (1993). The Japanese student and the foreign teacher. In P. Wadden (Ed.), $A$ handbook for teaching English at Japanese colleges and universities (pp. 27-33). New York, NY: Oxford University Press.

Osterman, G. L. (2014). Experiences of Japanese university students' willingness to speak English in class: A multiple case study. SAGE Open, 4(3), 1-13. doi:10.1177/2158244014543779

Peeters, W. (2018). Applying the networking power of Web 2.0 to the foreign language classroom: A taxonomy of the online peer interaction process. Computer Assisted Language Learning, 31(8), 905-931. doi:10.1080/09588221.2018.1465982 
Piniel, K., \& Albert, Á. (2018). Advanced learners' foreign language-related emotions across the four skills. Studies in Second Language Learning and Teaching, 8(1), 127-147. doi:10.14746/ssllt.2018.8.1.6

Sampson, R. J. (2018). The feeling classroom: diversity of feelings in instructed L2 learning. Innovation in Language Learning and Teaching, 14(3), 203-217. doi:10.1080/17501229.2018.1553178

Shachter, J. M. (2018). Tracking and quantifying Japanese English language learner speaking anxiety. The Language Teacher, 42(4), 3-7. doi:10.37546/jalttlt42.4-1

Shea, D. P. (2017). Compelled to speak: Addressing student reticence in a university EFL classroom. The Asian Journal of Applied Linguistics, 4(2), 173-184. Retrieved from https://caes.hku.hk/ajal/index.php/ajal/article/view/451

Stallard, P. (2002). Think good - feel good: A cognitive behavioural therapy workbook for children and young people. Chichester, UK: John Wiley \& Sons, Ltd.

Stallard, P. (2009). Anxiety: Cognitive behaviour therapy with children and young people. London, UK: Routledge.

Stallard, P. (2019). Thinking good, feeling better: A cognitive behaviour therapy workbook for adolescents and young adults. New Jersey, NJ: John Wiley \& Sons.

Teeter, J. L. (2017). Improving motivation to learn English in Japan with a self-study shadowing application. Languages, 2(9), 1-27. doi:10.3390/languages2040019

Toyama, M., \& Yamazaki, Y. (2018). Exploring the components of the foreign language classroom anxiety scale in the context of Japanese undergraduates. Asian-Pacific Journal of Second and Foreign Language Education, 3(4), 1-27. doi:10.1186/s40862018-0045-3

Wadden, P. (Ed.) (1993). A handbook for teaching English at Japanese colleges and universities. New York, NY: Oxford University Press.

Westbrook, D., Kennerley, H., \& Kirk, J. (2011). An introduction to cognitive behaviour therapy: Skills and applications. London, UK: Sage.

Yoneyama, S. (1999). The Japanese high school: Silence and resistance. London, UK: Routledge. 
Journal for the Psychology of Language Learning, Volume 2, June 2020, pp. 57-89. ISSN: 2642-7001. http://www.iapll.com/journal

\section{Appendices}

\section{Appendix A}

Example of the Questionnaire: Scenario 2

Scenario 2: You want to say something in English in class but don't.

8) What kind of emotions would you experience in this situation? Mark the scale with an ' $\mathrm{X}$.

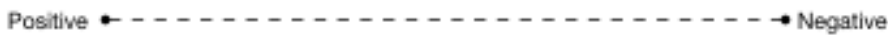

9) Please name the emotions (one or more) you would feel in this situation (maximum 10 words).

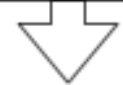

10)Why do you think you would feel this way? Please explain in a few words.

12) If the answer to 11 is 'yes' (you encountered this situation or something like it betore), how did you feel? Please explain in a few words.

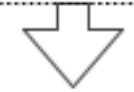

13) Is it common for you to feel this way in this kind of situation? Mark the scale with an ' $\mathrm{X}$ '.

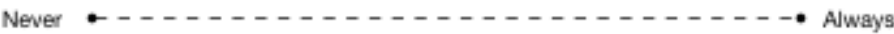

14) If you tried to manage your emotions in this situation, how did you do $s o$ ? (maximum 30 words). 
Journal for the Psychology of Language Learning, Volume 2, June 2020, pp. 57-89. ISSN: 2642-7001.

http://www.iapll.com/journal

Appendix $B$

Responses to Questionnaire Question 10

\begin{tabular}{|c|c|}
\hline Category & Response \\
\hline $\begin{array}{l}\text { Unable to talk due to belief in lack of linguistic } \\
\text { skills }\end{array}$ & $\begin{array}{l}\text { I am worried about if my grammar is correct, } \\
\text { and I am mortified when I cannot find phrases } \\
\text { and stumble over my words } \\
\text { Because I have more unknown words than other } \\
\text { people but I do not improve it } \\
\text { I feel sorry every time I ask ELI teachers. Also, I } \\
\text { cannot respond because a the lack of my } \\
\text { vocabulary and grammar } \\
\text { I cannot find words } \\
\text { I think the reason why I cannot convey what I } \\
\text { want to say in English is because my English } \\
\text { skills are low } \\
\text { I am not sure whether what I am saying can be } \\
\text { understood } \\
\text { I cannot come up with words I want to say } \\
\text { I wanted to say something, but because I } \\
\text { person } \\
\text { I have a thing that I want to say though I can't } \\
\text { because I do not know vocabulary } \\
\text { I in because I do not know how to say it in } \\
\text { vocabulary }\end{array}$ \\
\hline
\end{tabular}




\begin{tabular}{|c|c|}
\hline & $\begin{array}{l}\text { Not sure my English will be enough to get } \\
\text { across my message. } \\
\text { I think too much about grammar, and then } \\
\text { the words don't come out. } \\
\text { Even though there was something that I had } \\
\text { in my head that I wanted to say, there is no } \\
\text { point to all this if you can't find the words to } \\
\text { say it. } \\
\text { I don't understand grammar, }\end{array}$ \\
\hline $\begin{array}{l}\text { Negative feelings due to belief in an inability to } \\
\text { speak (no specific cause given) }\end{array}$ & $\begin{array}{l}\text { Because I have something that I want to say but } \\
\text { I cannot tell in English } \\
\text { I cannot say in English even though I can } \\
\text { prepare what I want to say in Japanese } \\
\text { Because I cannot say what I want to say } \\
\text { Because I can study vocabulary by myself but I } \\
\text { cannot use it (in an actual conversation) } \\
\text { I am irritated because I cannot say. It is not } \\
\text { because I do not say } \\
\text { Because I think it is a waste that I have } \\
\text { something that I want to say, however I cannot } \\
\text { say it (in English) } \\
\text { I cannot come up with (something) even though I } \\
\text { want to speak English } \\
\text { I feel miserable because I cannot say what I } \\
\text { want to say } \\
\text { Because I want to say (in English) but I can't } \\
\text { I know the answer but I cannot talk about it } \\
\text { I have a dilemma - want to speak but can't. }\end{array}$ \\
\hline
\end{tabular}




\begin{tabular}{|c|c|}
\hline & $\begin{array}{l}\text { Even though I want to say something but I } \\
\text { can't. }\end{array}$ \\
\hline Lacking confidence / agency & $\begin{array}{l}\text { I am not confident in my English } \\
\text { Because I have no confidence to convey what I } \\
\text { want to say } \\
\text { I cannot speak (English) because of a lack of } \\
\text { confidence in my English skills. I cannot say } \\
\text { what I want to say as I wish to, and I am } \\
\text { irritated- I want to speak better } \\
\text { Ifeel my powerlessness } \\
\text { I don't have confidence in my English. } \\
\text { No confidence in my ability } \\
\text { I don't have the confidence to communicate. } \\
\text { Embarrassed to speak English in front of my } \\
\text { friends, so I get frustrated by losing my } \\
\text { interest in speaking. } \\
\text { Not because I made mistakes, but because } \\
\text { my speaking wasn't smooth I lost my } \\
\text { confidence and was hard on myself. } \\
\text { Despite the people around me saying things, } \\
\text { No confidence to speak a foreign language. }\end{array}$ \\
\hline Fear of negative evaluations & $\begin{array}{l}\text { Because I am anxious about how people think } \\
\text { about my opinion } \\
\text { Because I imagine when I make mistakes } \\
\text { Feel unsure because I don't know whether } \\
\text { my English is correct or not. } \\
\text { I might make a mistake. }\end{array}$ \\
\hline
\end{tabular}




\begin{tabular}{|c|c|}
\hline & $\begin{array}{l}\text { I get anxious about what to do if I make a } \\
\text { mistake. } \\
\text { If I have the chance to go and start a } \\
\text { conversation, I will go. I will do it if it is } \\
\text { necessary, but I still worry about making } \\
\text { mistakes. }\end{array}$ \\
\hline Belief in a lack of ability related to study & $\begin{array}{l}\text { Because people around me are improving their } \\
\text { English skills a lot. I cannot improve my English } \\
\text { even though I am also studying hard } \\
\text { I cannot see improvement although I study } \\
\text { English every day } \\
\text { Because I can't think of what to say quickly. } \\
\text { Because I feel like I didn't study enough. } \\
\text { Even though I want to talk, I have no } \\
\text { speaking ability, and the words don't come } \\
\text { out. } \\
\text { Just as I thought; I don't have enough } \\
\text { ability. }\end{array}$ \\
\hline Feeling unable to communicate & $\begin{array}{l}\text { The atmosphere which makes it difficult to utter } \\
\text { makes me silent, and it makes me sad } \\
\text { I wanted to ask something but I didn't. } \\
\text { What a waste, because I had the chance to } \\
\text { speak English. } \\
\text { I had something to say but didn't. } \\
\text { I can't get across my feelings. }\end{array}$ \\
\hline Negative feelings (no specific cause) & $\begin{array}{l}\text { I am on the edge whether I say or not (what I } \\
\text { want to tell) } \\
\text { Because it does not go well } \\
\text { Because I am irritated }\end{array}$ \\
\hline
\end{tabular}


Journal for the Psychology of Language Learning, Volume 2, June 2020, pp. 57-89. ISSN: 2642-7001. http://www.iapll.com/journal

\begin{tabular}{|l|l|}
\hline & Because it's difficult. \\
\hline Positive / neutral & $\begin{array}{l}\text { I do not know because I have never been in that } \\
\text { situation }\end{array}$ \\
\hline Wecause I focus on their good looks. \\
\hline $\begin{array}{l}\text { Even though it is regrettable that I didn't say } \\
\text { what I wanted to say, I think about trying } \\
\text { harder to learn more vocabulary and using } \\
\text { the English I know to communicate. }\end{array}$ \\
$\begin{array}{l}\text { There was something I wanted to say but I } \\
\text { didn't, so how can I improve my } \\
\text { conversation skills, this isn't fun. }\end{array}$ \\
\hline
\end{tabular}

